\title{
Controle do Aedes: criação, recepção e percepções de campanhas audiovisuais em saúde pública em diferentes comunidades do Brasil
}

\author{
Aedes control: creation, reception and perceptions of public health \\ audiovisual campaigns in different communities of Brazil
}

Ádria Jane Albarado (http://orcid.org/0000-0003-2519-7690) ${ }^{1}$

Ana Valéria Machado Mendonça (http://orcid.org/0000-0002-1879-5433) ${ }^{1}$

Elizabeth Alves de Jesus (http://orcid.org/0000-0002-2731-5155) ${ }^{1}$

Maria Fátima de Sousa (https://orcid.org/0000-0001-6949-9194) ${ }^{1}$

${ }^{1}$ Laboratório de

Informação, Educação e Comunicação em Saúde, Universidade de Brasília. Campus Darcy Ribeiro, Cidade Universitária. 70910900 Brasília DF Brasil. adria.albarado@gmail.com

\begin{abstract}
In order to understand the communication strategy adopted by the Ministry of Health to prevent diseases caused by Aedes and to analy$z e$ the perception of the community regarding the videos on dengue, chikungunya and Zika aired between 2014 and 2017, a qualitative analysis was performed based on an in-depth interview with a key informant from the Ministry of Health Communication Center and conversation circles with the community in four Brazilian regions. The strategy adopted by the Ministry relies on the Hypodermic Needle Theory due to financial and logistical issues, but the analyzed campaigns did not reach the majority of participants in the circles. The latter consider that the most important information in prevention campaigns is related to care and not possible sequelae, different from what was affirmed by the key informant. The community considers the regionalization and the approach of socio-environmental, cultural and economic characteristics to be important, but the Ministry of Health does not consider the regionalization of campaigns to be effective. It is concluded that the videos do not meet the needs of the population and should be used in an integrated manner with other types of information, education and communication actions in health for effective disease control.
\end{abstract}

Key words Disease prevention, Aedes, Health communication, Qualitative research
Resumo Com a finalidade de compreender a estratégia de comunicação adotada pelo Ministério da Saúde para a prevenção de doenças causadas pelo aedes e analisar a percepção da comunidade quanto aos vídeos sobre dengue, chikungunya e Zika veiculados entre 2014 e 2017, apresentase análise qualitativa realizada a partir de uma entrevista em profundidade com informante-chave do Núcleo de Comunicação do Ministério da Saúde e de rodas de conversa com a comunidade de quatro regiões brasileiras. A estratégia adotada pelo Ministério apoia-se na Teoria Hipodérmica por questões financeiras e logísticas, mas campanhas analisadas não alcançaram a maioria dos participantes das rodas. Estes julgam que as informações mais importantes em campanhas de prevenção são os cuidados e não as possíveis sequelas, diferente do que foi argumentado pelo(a) informante-chave. A comunidade considera a regionalização e a abordagem de características socioambientais, culturais e econômicas importantes, mas o MS não considera a regionalização de campanhas efetiva. Conclui-se que os vídeos não suprem as necessidades da população e devem ser utilizados de forma integrada a outras ações de informação, educação e comunicação em saúde para a eficácia do controle das doenças.

Palavras-chave Prevenção de doenças, Aedes, Comunicação em saúde, Pesquisa qualitativa 


\section{Estabelecendo contextos}

Comunicação e saúde possuem aproximações desde 1920, época em que o modelo de saúde dominante tinha na propaganda e na educação sanitária estratégias de enfrentamento das doenças no Brasil e no mundo ${ }^{1}$. O Ministério da Saúde (MS) realiza, histórica e tradicionalmente, campanhas públicas de comunicação no Brasil e, com o surgimento da febre chikungunya, em 2014, e do vírus Zika e sua relação com o aumento de casos de microcefalia em bebês cujas mães foram infectadas em $2015^{2}$, viu-se uma expansão significativa de propagandas televisivas contra o vetor das referidas arboviroses. Isso porque diante do cenário de tripla carga de doença - dengue, chikungunya e Zika -, o grande desafio dos governantes foi implementar ações de prevenção eficazes, bem como informar a população quanto aos riscos e à importância da colaboração para o controle dos vetores destas arboviroses.

Há muito tempo utilizadas como instrumentos no combate a endemias, campanhas televisivas de saúde baseiam-se em uma das primeiras teorias da comunicação de massa, a Teoria Hipodérmica. Esta faz parte dos estudos denominados Mass Research Communication, realizados inicialmente entre 1920 e 1940, a partir de paradigmas psicológicos, sociológicos e antropológicos $^{2}$. O principal objetivo destes estudos era a investigação dos efeitos da exposição aos meios de comunicação de massa sobre os modos de percepção e comportamento das pessoas, bem como seu impacto sobre a cultura, as formas de organização social, política e econômica ${ }^{3,4}$.

Há cisões quanto à função das campanhas na saúde pública. Não se nega o papel estratégico, nem o potencial que têm, porém, há estudos que demonstram o quão são limitadas, principalmente para a transformação de atitudes, práticas sociais e ideologias ${ }^{5}$. Em geral, campanhas privilegiam anúncios informativos para prevenir doenças ${ }^{6}$ e as divergências não surpreendem se observadas as perspectivas da gestão e da população em seus respectivos contextos políticos e sociais.

A partir de autores dedicados à metodologia e ao tema empregados neste estudo, fruto de investigação de mestrado, a comunicação em saúde pode ser definida como campo de estudos que se refere a processos dialógicos e à utilização de estratégias comunicacionais, os quais devem respeitar os direitos à informação, à educação e à saúde. Sua finalidade inclui a prevenção de enfermidades, o incentivo à cidadania por meio da participação social, da transparência na gestão, bem como a promoção da melhoria da qualidade de vida das pessoas em diferentes contextos sociais, por meio de relações interpessoais, da mídia e do conhecimento ${ }^{7}$.

Como a vigilância em saúde e as campanhas se dão em âmbito público, um conceito que apoia as discussões nesta investigação é o de comunicação pública. Bucci ${ }^{8}$ afirma que esta é composta de ações informativas e interlocuções, pesquisas de opinião, colocadas em prática com recursos públicos e a partir de decisões transparentes e inclusivas. Além disso, o autor afirma que estas ações devem ser abertas à fiscalização, tanto da sociedade quanto dos órgãos de controle, em especial, às críticas e aos apelos da sociedade civil organizada. No tocante à função da comunicação pública, Bucci ${ }^{8}$ pontua que ela "existe para promover o bem comum e o interesse público".

$\mathrm{O}$ conceito adotado à comunicação de riscos é o do grupo de trabalho de comunicação do Regulamento Sanitário Internacional (RSI) da Organização Mundial da Saúde (OMS), que aponta Comunicação dos Riscos como processo de troca de informação em tempo real, aconselhamento e pareceres entre peritos ou funcionários públicos e pessoas cuja sobrevivência, saúde ou bem-estar econômico ou social estejam sob ameaça. O objetivo desta comunicação é colaborar para que as pessoas em situação de risco sejam capazes de tomar decisões informadas para diminuir os efeitos da ameaça, bem como adotem medidas adequadas para se prevenir, buscando mudanças de comportamento positivas e mantendo a confiança ${ }^{9}$.

Os resultados aqui apresentados se originam de uma investigação inserida junto ao Projeto Arbocontrol, financiado pelo Ministério da Saúde, e realizado em parceria com a Universidade de Brasília (UnB), no âmbito do Laboratório de Educação, Informação e Comunicação em Saúde (LabECoS) e do Núcleo de Estudos em Saúde Pública (Nesp) da UnB. Dele, integra o subprojeto "Gestão da informação, educação e comunicação no controle das arboviroses dengue, Zika e chikungunya", que traz entre seus objetivos conhecer as atividades e as práticas realizadas em relação às referidas ações de comunicação em saúde.

A partir do projeto de base, busca-se compreender a estratégia de comunicação adotada pelo Ministério da Saúde para a prevenção de doenças causadas pelo aedes. Além disso, pretende-se analisar a percepção da comunidade quanto às campanhas sobre as arboviroses dengue, chikungunya e Zika veiculadas pelo MS no período de 2014 a 2017. A análise da percepção dá-se a partir de relatos originados em rodas de conversa com munícipes de Vilhena-Rondônia; João Pessoa-Paraíba; Anápolis-Goiás; Cascavel-Paraná; 
das regiões Norte, Nordeste, Centro-oeste e Sul brasileiras, respectivamente.

\section{Métodos}

O paradigma metodológico deste relato de pesquisa é o compreensivo-interpretativo. Para Minayo et al. ${ }^{10}$, essa teoria responde questões qualitativas e coloca no centro a compreensão da realidade humana vivida socialmente. Suas bases teórico-metodológicas foram desenvolvidas por Max Weber e o marco para essa corrente foi a sua definição de Sociologia. Investiga, portanto, as expressões humanas presentes nas relações, nos sujeitos e nas representações. Refere-se também à vida das pessoas e lida com "[...] o universo de significados, motivos, aspirações, crenças, valores e atitudes, o que corresponde a um espaço mais profundo das relações, dos processos e dos fenômenos que não podem ser reduzidos à operacionalização de variáveis", bem como "[...] aprofunda-se no mundo dos significados das ações e relações humanas" ${ }^{10}$.

Por sua natureza aplicada, esta pesquisa buscou produzir conhecimentos dirigidos à gestão da comunicação em saúde e ao uso de materiais audiovisuais para a prevenção e o controle das arboviroses dengue, chikungunya e Zika. O percurso adotado no processo investigativo deu relevância ao pensamento que "fornece bases para uma interpretação dinâmica e totalizante da realidade, já que estabelece que os fatos sociais não podem ser entendidos quando considerados isoladamente, abstraídos de suas influências políticas, econômicas, culturais" ${ }^{11}$.

A escolha metodológica se deu pela complexidade do fenômeno, pois aborda um problema de saúde pública para o qual a mudança de hábitos é crucial à sua resolução. Trata-se de um estudo que envolve objetivos descritivos sobre a compreensão e a avaliação das pessoas com relação às campanhas. Portanto, é imprescindível considerar as subjetividades dos atores e realidades sobre os quais o problema se desenvolve. Para tanto, articula as técnicas e os procedimentos das pesquisas bibliográfica, documental e observacional $^{12}$, uma vez que a equipe de pesquisa teve participação direta com a população dos municípios visitados, a fim de obter informações sobre suas percepções quanto às campanhas, aos cuidados de prevenção e ao controle das arboviroses.

\section{Coleta de dados}

A entrevista em profundidade foi a técnica empregada para coletar informações junto ao in- formante-chave da coordenação da Assessoria de Comunicação do Ministério da Saúde. A referida entrevista foi solicitada via email institucional - disponível no portal do Ministério da Saúde - após a realização da análise das campanhas de prevenção às arboviroses e observações de lacunas identificadas em um estudo anterior ${ }^{7}$, lacunas estas que só poderiam ser esclarecidas com os responsáveis pela criação das peças. A partir da análise citada também foi feita a elaboração do roteiro com questões norteadoras para a realização da entrevista, cuja duração foi de duas horas. O áudio da conversa foi gravado, transcrito e codificado com a sigla "IC", de informante-chave.

Roda de conversa foi a segunda técnica de coleta de dados empregada na pesquisa. Esta consiste em um "método de participação coletiva de debate acerca de determinada temática a partir da qual é possível dialogar com os sujeitos, que se expressam e escutam seus pares e a si mesmos por meio do exercício reflexivo" ${ }^{13}$. Foram realizados dois pilotos para alinhamento do roteiro das rodas de conversa em Brasília-DF e em Luziânia-GO.

Para esta análise foram investigadas quatro atividades realizadas em Vilhena-RO; João Pessoa-PB; Anápolis-GO; e, Cascavel-PA, que foram codificadas como "RCV", "RCJ", "RCA" e "RCC", respectivamente. Nas siglas, " $R$ " significa "roda" e as demais letras correspondem às iniciais das cidades onde ocorreram as respectivas rodas de conversa. Os municípios investigados foram incluídos conforme critérios do Projeto Arbocontrol, ao qual se integra esta análise ${ }^{14}$.

Foram consideradas as seguintes questões: localização urbana segundo a Classificação e Caracterização dos Espaços Rurais e Urbanos do Brasil ${ }^{15}$; participação dos respectivos municípios no Levantamento Rápido de Índices para Aedes aegypti (LIRAa) nos anos de 2016 e 2017; e adesão do município ao Programa Saúde na Escola (PSE). A articulação do campo foi feita com antecedência, por meio de ligações telefônicas e apoio de secretarias de saúde e de educação, bem como de lideranças comunitárias ou outros atores estratégicos à mobilização social desses participantes. Assim, foi agendada a ida dos pesquisadores ao município, conforme disponibilidade dos parceiros para recepção da equipe e observação de feriados municipais, dentre outros impeditivos. $\mathrm{Na}$ ocasião, os participantes convidados para as rodas de conversa encontravam os investigadores no local disponibilizado pelo município. Estes variaram entre salas de aula, ginásios, auditórios de centros de saúde e outros espaços.

Cada roda de conversa contou com dez pessoas e teve a duração de $1 \mathrm{~h} 30 \mathrm{~min}$. Os participan- 
tes eram maiores de 18 anos de idade; de ambos os sexos; responsáveis pela casa e residentes dos municípios visitados. A maioria dos participantes eram mulheres, negras, com idade entre $42 \mathrm{e}$ 66 anos, com ensino fundamental incompleto. Excluíram-se conselheiros de saúde, professores e profissionais de saúde, pois nos pilotos, observou-se que tais atores monopolizavam os diálogos, influenciando ou silenciando os demais participantes. Incluiu atividades de apresentação; aquecimentos inespecífico e específico; desenvolvimento - momento em que foram exibidos os filmes das campanhas sobre as arboviroses como elementos estimuladores do diálogo com os participantes -; e comentários para finalização ${ }^{16}$.

Os dados foram coletados de abril a junho de 2018. Além de questões sobre percepções quanto aos vídeos em si, a atividade abrangeu assuntos sobre práticas de educação, informação e comunicação em saúde do cotidiano dos participantes observadas nas campanhas e na revisão da literatura pertinente. A condução do trabalho em campo foi realizada por trios compostos por pesquisadores e estudantes de doutorado, mestrado e/ou iniciação científica, das áreas de Saúde Coletiva, Psicologia, Medicina ou Farmácia. Os diálogos foram gravados, transcritos e categorizados a partir de questões temáticas. Além disso, os pesquisadores adotaram o diário de campo para aprofundar a compreensão dos cenários visitados.

Conforme determina a Resolução $\mathrm{n}^{\circ} 466$, de 12 de dezembro de 2012, do Conselho Nacional de Saúde, o estudo observou os aspectos éticos relativos à pesquisa com seres humanos. Foi submetido ao Comitê de Ética em Pesquisa com Seres Humanos da Faculdade de Ciências da Saúde da UnB e aprovado em 20 de abril de 2018. Durante sua realização, os participantes foram informados sobre os objetivos da pesquisa e somente tornaram-se indivíduos da investigação após serem orientados sobre o Termo de Consentimento Livre e Esclarecido (TCLE), que teve uma via assinada e entregue pelos pesquisadores aos participantes da pesquisa.

\section{Análise e interpretação dos dados}

A estratégia analítica adotada na investigação é o da análise de conteúdo de Bardin ${ }^{17}$. A técnica explora o campo das comunicações e suas significações e revela elementos sublinhados em conteúdos explícitos para além das aparências e dos objetivos funcionais do que é comunicado em campanhas $^{17}$. Os resultados da entrevista e das rodas de conversa foram analisados e discutidos à luz da literatura pertinente.
Para este relato em particular, foram observadas questões desde a criação das campanhas audiovisuais - em especial relativas à entrevista com o informante-chave e com a comunidade, temas referentes aos vídeos apresentados nas rodas de conversa. Estes, abordaram as três arboviroses em campanhas publicadas em diferentes períodos. Os filmes foram coletados no portal do Ministério da Saúde e agrupados em dois blocos, um sobre prevenção, orientações e cuidados, e outro sobre personagens reais com relatos sobre as consequências da infecção pelas doenças.

As percepções e as respostas da entrevista em profundidade e das rodas de conversa foram agrupadas em cinco categorias temáticas a saber: 1) audiência; 2) objetivos, estética e informações; 3) representatividade e identificação; 4) cuidados, os quais contaram com as subcategorias facilidades, dificuldades e outros; e 5) qualidade das campanhas.

\section{Resultados e discussão}

Para a primeira categoria, consideraram-se as respostas dos participantes sobre terem assistido ou não aos filmes e, em qual mídia, em caso de respostas positivas. Os aspectos teóricos e conceituais dessa categoria envolvem os estudos da Mass Communication Research ${ }^{3,4,9,18,19}$ e do Pensamento Contemporâneo Latino-americano sobre recepção e mediação ${ }^{20-22}$.

$\mathrm{Na}$ segunda categoria, incluíram-se percepções sobre a compreensão dos objetivos das campanhas a exemplo, se eram informativas ${ }^{23}$, sensacionalistas, sobre comunicação de riscos ${ }^{9}$, dentre outras relacionadas à prevenção e ao controle das arboviroses. No quesito sensacionalismo, considerou-se a definição que afirma que se trata do uso e efeito de assuntos sensacionais com a intenção de causar impacto e chocar a opinião pública ${ }^{24}$. Este é um modo atual de produção discursiva da informação, acionado a partir de "critérios de intensificação e exagero gráfico, temático, linguístico e semântico, contendo em si valores e elementos desproporcionais, destacados, acrescentados ou subtraídos no contexto de representação e construção do real social" 25 .

A terceira categoria, por sua vez, reuniu pontos sobre o reconhecimento das respectivas realidades cultural, social, econômica, geográfica, dentre outros aspectos retratados nos vídeos. $\mathrm{O}$ suporte para esta categoria vem dos determinantes sociais e ambientais em saúde ${ }^{26}$.

No tocante aos 'cuidados', a quarta categoria considerou as ações dos participantes para a pre- 
venção e o controle das arboviroses. Estas foram divididas nas subcategorias: facilidades de cuidado; dificuldades de cuidado e outros cuidados. $\mathrm{Na}$ primeira, incluíram-se respostas e temas que facilitam as ações; na segunda, as que dificultavam; e, na terceira, outros, não destacados nas campanhas. Nesta perspectiva, compreende-se cuidado como um " [...] 'modo de fazer na vida cotidiana' que se caracteriza pela 'atenção', 'responsabilidade', 'zelo' e 'desvelo' 'com pessoas e coisas' em lugares e tempos distintos de sua realização" ${ }^{27}$.

A quinta categoria, enfim, abrange aspectos sobre a qualidade das campanhas, em especial quanto ao atendimento de seu objetivo, linguagem, locação e enredo empregados, bem como conteúdo. Para tanto, as percepções e as avaliações dos participantes foram interpretadas sob a ótica da Comunicação Pública e com base na afirmações de Zémor traduzidas e comentadas por Brandão $0^{28}$ : "Ouvir o usuário significa ter capacidade para dar uma resposta não estereotipada, levar em consideração o usuário e o conteúdo preciso do problema que ele está colocando" e "Ao mesmo tempo em que ele respeita e se submete à autoridade das instituições públicas, ele protesta sobre a falta de informação, ou sobre suas mensagens mal construídas, incompletas ou mal divulgadas" 28 .

Os resultados demonstram que a televisão não é mais decisiva para elevar a audiência das campanhas de saúde pública. Em João Pessoa - $\mathrm{PB}$, apenas três participantes afirmaram ter visto os vídeos. Vilhena-RO foi o local onde mais pessoas viram as peças, seguida de Anápolis-GO. Os demais participantes das rodas não lembraram de tê-las visto ou simplesmente não as assistiram, ainda que sejam ações sazonais e fiquem no ar pelo menos por quatro meses.

A entrevista confirmou que a principal estratégia de comunicação do MS baseia-se na Teoria da Bala Mágica:

O meu objetivo, e tenho que ter isso muito claro quando trabalho no Governo Federal, eu tenho que atingir o maior número de pessoas possíveis com uma mesma mensagem. (IC)

Para alcançar tal objetivo, investe maior parte de seus recursos na divulgação de campanhas na TV aberta ${ }^{29}$, embora saiba que esta ação não tenha mais a efetividade esperada:

A TV perdeu muito espaço e as pesquisas de comunicação, de mídia, indicam isso. Não é mais 100\% como era antigamente [...] ela ainda é o espaço de maior credibilidade. (IC)

Os achados das rodas de conversa demonstram as falhas desta estratégia. O MS ainda trata a recepção como mera etapa do processo de comu- nicação verticalizado e institucional que pratica, enquanto o que temos hoje é, na verdade, uma audiência menos controlada, dotada de acesso às mídias alternativas, que produz e escolhe o que quer consumir da comunicação diante da ampliação do acesso, em especial, o conquistado via internet ${ }^{29,30}$.

No tocante aos objetivos, estética e informações, as pessoas demonstraram ter clareza que as mensagens objetivam mobilizar para a prevenção e orientar sobre cuidados e ações para eliminar criadouros do mosquito, bem como a capacidade de identificar as histórias de personagens reais. Destaca-se que a estética dos filmes não é diretamente apontada, mas a forma como as pessoas a observam pode ser notada mediante as palavras usadas para descrevê-las, num paradoxo entre prevenção/cuidado versus perdas/sofrimento.

As peças com tom escuro falam sobre perdas e sequelas, bem como o som dramático ao fundo, demonstram a adoção de uma abordagem mais sensacionalista, devido à necessidade de a gestão mostrar a seriedade do problema:

Foi intencional, para quebrar aquele padrão de comercial de TV, que é tudo cerveja, aquela felicidade toda. Para. Vamos refletir, porque é um sofrimento para aquela pessoa e é real. É uma pessoa verdadeira, pode acontecer com qualquer um. (IC)

Alguns participantes citaram que as campanhas têm mesmo que 'chocar', pois 'infelizmente' a população só se preocupa em fazer algo se seu incentivo for o medo.

Com relação à categoria representatividade e identificação, os participantes de Vilhena-RO e João Pessoa-PB não comentaram ou responderam quando perguntados se percebiam que a realidade apresentada nos vídeos no que diz às casas, ruas, objetos, dentre outras coisas, se pareciam com a deles ou se eles se identificavam com a situação. Um silêncio muito revelador. Para além das diferenças demonstradas no desenho dos municípios e nas respostas dadas pelos próprios participantes das rodas apresentados anteriormente, as descrições dos diários de campo dos pesquisadores revelaram o quão há diferenças nas realidades dos municípios, inclusive, pelas regiões do país.

As campanhas pouco se preocupam com os determinantes sociais de saúde das respectivas regiões, principalmente sobre o território e o ambiente ${ }^{26}$. As peças trazem, em grande maioria, locais pavimentados; limpos; residências de concreto; acesso à coleta de lixo, transporte público e água tratada. O que não é padrão na realidade do Brasil, sobretudo quando analisada por regiões ou dados diretamente ao saneamento básico. Dados do Perfil dos Municípios Brasileiros (Munic) 
de 2017 mostram que somente $41,5 \%$ do total de 5.570 municípios brasileiros possuíam Plano Municipal de Saneamento, sendo que Norte e Nordeste estão entre as que possuem menos municípios com o plano ${ }^{31}$.

Comentários dos próprios participantes corroboram a relevância de considerar os determinantes sociais e a estratégia da regionalização ao apontarem diferenças que vão desde o uso de 'lajes' à cultura. Além das situações sobre os determinantes, a identificação poderia colaborar para aumentar a mobilização, pois é fato que quando as pessoas se reconhecem e se veem representadas, a sensação de corresponsabilização e pertencimento aumenta ${ }^{29}$. Entretanto, o MS mantém a massificação das mensagens:

A gente tenta trazer personagens que representem a população, porque aí você representa um pouco da regionalização, mas ainda assim é uma campanha de massa. (IC)

A regionalização na comunicação em saúde é fragilizada e a articulação com gestores locais é falha, principalmente no tocante à logística das ações de comunicação do âmbito federal por deficiências na coordenação temporal e logística de distribuição de material para estados e municípios, em especial, os impressos ${ }^{32}$. A insistência no formato de 1920 impede a gestão de pensar alternativas e mais uma vez demonstra a necessidade de tais ações se preocuparem com a realidade do país e buscarem meios efetivos para informar e orientar sobre cuidados na prevenção e no controle da dengue, chikungunya e Zika. Embora a regionalização não se demonstre eficaz para a gestão, faz-se necessária pela situação de saúde da população das diferentes regiões do país, assolada, sazonalmente, pelas arboviroses.

Sobre os cuidados, as pessoas afirmaram, em unanimidade, que a limpeza é a ação fácil, seja da própria casa ou de utensílios como vasos, caixas d'água ou potes de animais. A limpeza das calhas foi apontada como dificuldade, principalmente porque para limpá-la, é preciso subir escadas. Uma situação discutida nas rodas de João Pessoa-PB, Anápolis-GO e Cascavel-PR, relaciona-se à orientação 'converse com seus vizinhos', uma problemática dificuldade, inclusive com relatos de violência e medo:

Você vê, eu mesma entrava naquela chácara [...] O dia que eu entrei, o vigia falou: 'A mulher mandou meter fogo em quem entrar'. (RCA)

Outros cuidados e práticas adotados pelos participantes e não citados objetivamente nos vídeos apresentados nas rodas de conversa ${ }^{2}$ se referiram a práticas de controle químico dos insetos com água sanitária, repelentes e inseticidas industrializados ou naturais, como a queima de casca de laranja e alfazema. A partir dos relatos observa-se que as campanhas audiovisuais veiculadas nacionalmente não têm suprido a necessidade de informação e orientação por parte da população que, por sua vez, acaba adotando práticas inclusive perigosas devido às 'velhas questões da desinformação' ${ }^{2}$.

Entretanto, o MS optou por não mais abordar cuidados ou compartilhar orientações nas campanhas nacionais:

As pessoas não queriam mais ouvir sobre os criadouros, aquilo que a gente falou durante anos [...] 'O que vocês querem ouvir então?' 'Queremos ouvir pessoas reais nessas campanhas' e aí veio o estalo, precisamos contar histórias reais, pois as pessoas sabem o que têm que fazer, mas elas não fazem'. (IC)

Nas rodas de conversa, todavia, as informações mais importantes para a população eram sobre os cuidados para prevenção, orientações de como eliminar os criadouros e buscar ajuda nas unidades de saúde frente a qualquer sintoma das doenças. A maioria das pessoas então, ressaltou os cuidados, o que contradiz, diretamente, a afirmação do MS.

Por fim, quanto à qualidade das campanhas, segundo a comunidade é preciso ir além dos vídeos e, quando utilizá-los, fazê-lo estrategicamente, de forma integrada a outras ações, principalmente em regiões mais problemáticas - e com o auxílio dos agentes de saúde:

Eu acho que as campanhas, pelo menos que a gente tem, são satisfatórias [...] porque eu entendo que essa questão do cuidado é mais cultural, muda muito de região para região. Por exemplo, estamos aqui na cidade em uma região aonde a estrutura de coleta de lixo é satisfatória, aonde o cuidado com os terrenos baldios também não deixa a desejar, mas há cidades em que não há. Acho que se você massificar a instrução e a orientação em geral, não é bem a solução, mas sim ela focalizar. As áreas mais deficitárias, onde o pessoal tem uma cultura de maior relaxamento e onde os focos são maiores [...] acho que precisam de um investimento maior que a gente. Mas no geral, também é necessário, claro. (RCC)

A necessidade do diálogo com profissionais de saúde para abordar questões sobre as arboviroses ficou evidente nas falas, inclusive com sugestões de como abordar as pessoas. O diálogo, enfim, é o que as pessoas mais precisam e sentem falta para se prevenirem e cuidarem de sua saúde e da comunidade. É claro que os esforços estratégicos de comunicação não podem dispensar as campanhas massivas, mas estas devem contar 
com ações dirigidas. "É fundamental garantir, através de forte comunicação interpessoal, que as mensagens massivas penetrem rapidamente as redes de conversação nas localidades, caso contrário, as próprias mensagens tendem a dispersar-se e a perder força" ${ }^{33}$. Isso é possível em encontros em que haja escuta e troca, feitos, basicamente porta a porta, olhando nos olhos das pessoas. As campanhas, mesmo quando produzidas e pré-testadas de modo planejado, pouco mudam comportamentos sociais em proporção aos investimentos que demandam.

\section{Considerações finais}

A população percebeu que somente a utilização de campanhas audiovisuais de massa não é suficiente para mobilizá-la, informá-la e orientá-la para controlar e prevenir a proliferação do mosquito aedes ou o surgimento de infecções por dengue, chikungunya e Zika vírus. Apesar de tratar-se da principal estratégia abordada pelo $\mathrm{Mi}$ nistério da Saúde, em especial se considerados os investimentos financeiros realizados, em quatro diferentes regiões a noção de "campanhas" é muito mais ampla que a veiculação de peças de 30 segundos em rede nacional. A percepção da população é a mesma que a de pesquisadores da área, elas não devem ser descartadas, porém, precisam ser repensadas, considerando os determinantes sociais, econômicos, culturais e ambientais das diferentes regiões brasileiras.

Outrossim, carecem ser articuladas e integradas a outras ações intrassetoriais de informação, educação e comunicação em saúde, em especial as que envolvem comunicação interpessoal e participação social. As pessoas pedem por ações de comunicação regionalizadas, baseadas no diálogo e no direito à informação e à comunicação, numa linguagem acessível e que transmita credibilidade e confiança, principalmente com médicos e enfermeiros responsáveis pelos primeiros cuidados em caso de adoecimento. Os relatos apontam ainda, a necessidade da comunicação se apresentar de forma transversal na saúde e de ser, neste contexto, uma preocupação que vai além da sensibilização por meio do medo e da tristeza, não somente nas abordagens para a prevenção de dengue, chikungunya e Zika, mas em todas as outras relativas ao cuidado individual e coletivo da saúde.

O foco na eliminação do vetor das doenças e o silêncio quanto aos fatores sociais e econômicos por parte do MS priorizam a prevenção a partir de dados epidemiológicos, todavia não contribuem para que as pessoas desenvolvam senso crítico quanto às suas reais necessidades de cuidados integrais à saúde e até mesmo repensem realidades sociais e relações com o ambiente enquanto cidadãos. Como apontado pelos participantes das rodas de conversa, é necessário maior integração entre os gestores do nível federal, estadual e municipal, bem como com setores além da saúde. Outro destaque é a sazonalidade das campanhas. Deve-se realizar ações contínuas para a prevenção das arboviroses em questão, não apenas no período em que há epidemia das doenças. Nesse sentido, focar na prevenção e na promoção da saúde dos indivíduos, antecipandose à reemergência das doenças, faz-se imperativo na comunicação em saúde.

\section{Colaboradores}

AJ Albarado e AVM Mendonça conceberam o estudo, AJ Albarado realizou a análise e a interpretação dos dados, escreveu a primeira versão, participou das revisões críticas e da preparação da versão final. EA Jesus participou da análise e interpretação dos dados, da escrita e da revisão crítica do texto. AVM Mendonça e MF Sousa supervisionaram a análise e interpretação dos dados, e fizeram a revisão da versão final. Todas as autoras aprovaram a versão final do manuscrito.

\section{Referências}

1. Araújo IS, Cardoso JM. Comunicação e saúde. Rio de Janeiro: Fiocruz; 2007.

2. Valle D, Pimenta DN, Aguiar R. Zika, dengue e chikungunya: desafios e questões. Epidemiol. Serv. Saúde [Internet]. 2016 Jun [acessado 2017 Nov 9]; 25(2):419-422. Disponível em: http://scielo.iec.gov.br/scielo.php?script=sci_arttext\&pi$\mathrm{d}=$ S1679-49742016000200419\&lng=pt. http://dx.doi. org/10.5123/S1679-49742016000200020.

3. Wolf M. Teorias das comunicações de massa. $6^{\mathrm{a}}$ ed. São Paulo: WMF Martins Fontes; 2012. 
4. Albuquerque A. Estudos de mídia. In: Citelli A, Berger C, Baccega MA, Lopes MIV, França VV, organizadores. Dicionário de Comunicação: escolas, teorias e autores. São Paulo: Contexto; 2014. p. 260-266.

5. Tóth M, Laro R. O potencial limitado das campanhas massivas de comunicação para a transformação de comportamentos sociais. In: Paulino FO, organizador. Comunicação e Saúde. Brasília: Casa das Musas; 2009. p. 45-53.

6. Vasconcelos WRM. Oliveira-Costa MS. Mendonça AVM. Promoção ou prevenção? Análise das estratégias de comunicação do Ministério da Saúde no Brasil de 2006 a 2013. Rev Eletron Comun Inf Inov Saúde [Internet]. 2016 jun. [acessado 2017 Abr 7];10;2. Disponível em: https://www.reciis.icict.fiocruz.br/index. php/reciis/article/view/1019

7. Albarado AJ, Prado EJ, Mendonça AVM. Um, dois, três - gravando: as campanhas audiovisuais do Ministério da Saúde sobre dengue, chikungunya e Zika de 2014 a 2017. Revista Eletrônica de Comunicação Informação \& Inovação em Saúde [Internet]. 2019 [acessado 2019 Maio 21];13:75-86. Disponível em: https:// www.reciis.icict.fiocruz.br/index.php/reciis/article/ view/1596/2254

8. Bucci E. O Estado de Narciso: a comunicação pública a serviço da vaidade particular. São Paulo: Companhia das Letras; 2015.

9. Hyer RN, Covelho VT. Comunicação eficaz com a mídia durante emergências de Saúde Pública: um manual da OMS. Brasília: Ministério da Saúde (MS); 2009.

10. Minayo MCS, Deslandes SF, Gomes R. Pesquisa Social: teoria, método e criatividade. Petrópolis: Editora Vozes; 2016.

11. Gil AC. Métodos e técnicas de pesquisa social. $7^{\mathrm{a}}$ ed. São Paulo: Editora Atlas SA; 2019.

12. Marconi MDA, Lakatos EM. Fundamentos de metodologia científica. 8a ed. São Paulo: Editora Atlas; 2017.

13. Moura AF, Lima MG. A Reinvenção da Roda: Roda de Conversa, um instrumento metodológico possível. Interfaces da Educ 2014; 5(15):24-35.

14. Albarado AJ, Mendonça AVM, Jesus EA, Fernandes N, Brito PT, Sousa MF. Análise da recepção de campanhas audiovisuais de saúde no Brasil: um estudo qualitativo sobre a percepção da população no controle do aedes. In: Anais do $8^{\circ}$ Congresso Ibero-americano de Investigação Qualitativa, 2019; Lisboa, Portugal. p. 1343-1354.

15. Instituto Brasileiro de Geografia e Estatística (IBGE). Pesquisa de Informações Básicas Municipais: Perfil dos Municípios Brasileiros. Rio de Janeiro: IBGE; 2018.

16. Rasera EF. Social constructionist perspectives on group work. Ohio: Taos Institute Publications; 2015.

17. Bardin L. Análise de conteúdo. Lisboa: Edições 70 LDA; 2011.

18. De Fleur M, Ball-Rokeach S. Teorias da Comunicação de Massa. Rio de Janeiro: Jorge Zahar Editor; 1993.

19. Mattelart A, Mattelart M. História das teorias da comunicação. $8^{\mathrm{a}}$ ed. São Paulo: Edições Loyola; 2005.

20. Temer ACRP, Nery VCA. Para entender as teorias da comunicação. Uberlândia: Edufu; 2009.

21. Berger CLBRK, Schwaab R. Escola Latino-americana de comunicação. In: Citelli A, Berger CLBRK, Baccega MA, De Lopes MIV, França VV, Camargo RZ, Bendassolli PF, organizadores. Dicionário de comunicação: escolas, teorias e autores. São Paulo: Editora Contexto; 2014. p. 200-209.
22. Jacks N, Ronsini VM. Pensamento Contemporâneo Latino-Americano. In: Citelli A, Berger CLBRK, Baccega MA, De Lopes MIV, França VV, Camargo RZ, Bendassolli PF, organizadores. Dicionário de comunicação: escolas, teorias e autores. São Paulo: Editora Contexto; 2014. p. 349-358.

23. Melo JM, Assis F. Gêneros e formatos jornalísticos: um modelo classificatório. Intercom-Revista Brasileira de Ciências da Comunicação 2016; 39(1):39-56.

24. Neiva E. Dicionário Houaiss de Comunicação e Multimídia: sensacionalismo. São Paulo: Publifolha; 2013.

25. Pedroso RN. A construção do discurso de sedução em um jornal sensacionalista. São Paulo: Annablume; 2001.

26. Filho AB, Buss PM, Esperidião MA. Promoção da Saúde e seus fundamentos: Determinantes Sociais Ação Intersetorial e Políticas Públicas Saudáveis. In: Paim JS, Almeida-Filho N, organizadores. Saúde Coletiva Teoria e Prática. Rio de Janeiro: MedBook; 2014. p. 305-326.

27. Pinheiro R. Dicionário da educação profissional em saúde: cuidado. Rio de Janeiro: Fundação Oswaldo Cruz; 2009.

28. Brandão E. A Comunicação Pública: o cidadão, o Estado e o Governo. In: Martins L, Brandão E, Matos H, Duarte J, Zémor P. Comunicação Pública. Brasília: Casa das Musas; 2003. p. 76-103.

29. Albarado AJ. Campanhas audiovisuais do Ministério da Saúde contra dengue, Zika e chikungunya nos anos de 2014 a 2017: análise das estratégias de comunicação em saúde [dissertação]. Brasília: Universidade de Brasília; 2018.

30. Tondato MP. Estudos de recepção e audiência. In: Citelli A, Berger CLBRK, Baccega MA, Lopes MIV, França VV, organizadores. Dicionário de comunicação: escolas, teorias e autores. São Paulo: Contexto; 2014. p. 304-312.

31. Instituto Brasileiro de Geografia e Estatística (IBGE). Pesquisa de Informações Básicas Municipais: Perfil dos Municípios Brasileiros. Rio de Janeiro: IBGE; 2018.

32. Montoro T. Retratos da comunicação em saúde: desafios e perspectivas. Interface Botuca$t u$ [periódico na internet] 2008 [acessado 2018 Jul 21]; 12(25):445-448. Disponível em: http:// www.scielo.br/scielo.php?script=sci_arttext\&pi$\mathrm{d}=$ S1414-32832008000200020\&lng=en\&nrm=iso.

33. Henriques MS, Mafra RLM. Mobilização Social em Saúde: o papel da comunicação estratégica. In: Santos A. Venâncio D, organizadores. Caderno mídia e saúde pública. Belo Horizonte: Escola de Saúde Pública/FUNED; 2006. p.101-111.

Artigo apresentado em 10/03/2020

Aprovado em 15/04/2020

Versão final apresentada em 17/04/2020

Editores-chefes: Maria Cecília de Souza Minayo, Romeu Gomes, Antônio Augusto Moura da Silva 